\title{
Claude Favre de Vaugelas, Remarques sur la langue françoise
}

\section{Laura Rescia}

\section{(2) OpenEdition \\ 1 Journals}

\section{Edizione digitale}

URL: http://journals.openedition.org/studifrancesi/5924

DOI: 10.4000/studifrancesi.5924

ISSN: 2421-5856

Editore

Rosenberg \& Sellier

\section{Edizione cartacea}

Data di pubblicazione: 1 mai 2011

Paginazione: 162

ISSN: 0039-2944

\section{Notizia bibliografica digitale}

Laura Rescia, «Claude Favre de Vaugelas, Remarques sur la langue françoise», Studi Francesi [Online], 163 (LV | I) | 2011, online dal 30 novembre 2015, consultato il 08 janvier 2021. URL: http:// journals.openedition.org/studifrancesi/5924 ; DOI: https://doi.org/10.4000/studifrancesi.5924

Questo documento è stato generato automaticamente il 8 janvier 2021.

\section{(c) (i) (9)}

Studi Francesi è distribuita con Licenza Creative Commons Attribuzione - Non commerciale - Non opere derivate 4.0 Internazionale. 


\title{
Claude Favre de Vaugelas, Remarques sur la langue françoise
}

\author{
Laura Rescia
}

\section{NOTIZIA}

CLAUDE FAVRE DE VAUGELAS, Remarques sur la langue françoise, édition critique avec introduction et notes par Zygmunt MARZYS, Genève, Droz, 2009, pp. 1002.

1 Progettata nel 1975, come ci viene svelato nella prefazione, e protrattasi per molti anni in ragione della sua complessità, l'edizione critica delle celeberrime Remarques trova oggi una collocazione editoriale di grande qualità, destinata a divenire l'edizione di riferimento per un tempo che immaginiamo lungo almeno quanto la sua incubazione.

Al lettore viene data la possibilità di comparare, a lato del testo della princeps del 1647, la versione manoscritta (Ms 3105 conservato presso la Bibliothèque de l'Arsenal, di cui tuttavia non si specifica se sia autografo), in molti passaggi profondamente diversa dall'opera a stampa, a testimonianza di tutte le esitazioni di un Vaugelas che emerge da questo confronto come assai meno normativo di quanto finora ritenuto. Un esempio varrà per tutti: la celebre formula del bon usage, che si trova sia nel primo abbozzo della Préface che in due passaggi del testo a stampa, non appare nella versione manoscritta, fatto che consente a Marzys di retrodatare la sua prima occorrenza al 1637. Ancor più meritoria è la lunga messe di notazioni dell'editore scientifico, molte delle quali raccolgono il raffronto tra le opinioni di Vaugelas e il riflesso delle sue indicazioni nei testi letterari coevi, nelle grammatiche e teorizzazioni linguistiche fino a fine secolo. Una bibliografia ponderosa e un triplo, accuratissimo indice (nomi propri, parole e forme linguistiche, nozioni) completano questo eccellente lavoro. 